\title{
Article \\ Combination of Sorafenib and Transarterial Chemoembolization in Selected Patients with Advanced-Stage Hepatocellular Carcinoma: A Retrospective Cohort Study at Three German Liver Centers
}

\author{
Christine Koch ${ }^{1,2}$, Markus Göller ${ }^{1}$, Eckart Schott ${ }^{3}$, Oliver Waidmann ${ }^{1,2}$ (D), Mark op den Winkel ${ }^{4}$, \\ Philipp Paprottka ${ }^{4,5}$, Stephan Zangos ${ }^{6,7}$, Thomas Vogl ${ }^{6}$, Wolf Otto Bechstein ${ }^{8} \mathbb{D}$, Stefan Zeuzem ${ }^{1}$, \\ Frank T. Kolligs ${ }^{4,9}$ and Jörg Trojan ${ }^{1,2, *}$
}

check for updates

Citation: Koch, C.; Göller, M.; Schott, E.; Waidmann, O.; op den Winkel, M.; Paprottka, P.; Zangos, S.; Vogl, T.; Bechstein, W.O.; Zeuzem, S.; et al. Combination of Sorafenib and Transarterial Chemoembolization in Selected Patients with Advanced-Stage Hepatocellular Carcinoma: A Retrospective Cohort Study at Three German Liver Centers. Cancers 2021, 13, 2121. https:// doi.org/10.3390/cancers13092121

Academic Editor: Thomas Decaens

Received: 10 March 2021

Accepted: 26 April 2021

Published: 28 April 2021

Publisher's Note: MDPI stays neutral with regard to jurisdictional claims in published maps and institutional affiliations.

Copyright: (c) 2021 by the authors. Licensee MDPI, Basel, Switzerland. This article is an open access article distributed under the terms and conditions of the Creative Commons Attribution (CC BY) license (https:// creativecommons.org/licenses/by/ $4.0 /)$.
1 Department of Medicine 1, University Hospital Frankfurt, Goethe-University, Theodor-Stern-Kai 7, 60590 Frankfurt, Germany; christine.koch@kgu.de (C.K.); markus.goeller@uk-erlangen.de (M.G.); oliver.waidmann@kgu.de (O.W.); zeuzem@em.uni-frankfurt.de (S.Z.)

2 University Cancer Centre, University Hospital Frankfurt, Goethe-University, 60590 Frankfurt, Germany

3 Department of Gastroenterology, Hepatology and Diabetology, Internal Medicine II, HELIOS Hospital Emil von Behring, 14165 Berlin, Germany; eckart.schott@helios-gesundheit.de

4 Department of Medicine II, University Hospital, Ludwig Maximilians University, 81377 Munich, Germany; Mark.op.den.Winkel@med.uni-muenchen.de (M.o.d.W.); philipp.paprottka@mri.tum.de (P.P.); frank.kolligs@helios-gesundheit.de (F.T.K.)

5 Department of Interventional Radiology, Klinikum rechts der Isar, Technical University Munich, 80333 Munich, Germany

6 Department of Diagnostic and Interventional Radiology, University Hospital Frankfurt, Goethe-University, 60590 Frankfurt, Germany; stephan.zangos@af-k.de (S.Z.); thomas.vogl@kgu.de (T.V.)

7 Department of Radiology and Nuclear Medicine, Klinik am Eichert und Helfenstein Klinik, 73312 Göppingen, Germany

8 Department of General and Viszeral Surgery, University Hospital Frankfurt, Goethe-University, 60590 Frankfurt, Germany; wolf.bechstein@kgu.de

9 Department of Internal Medicine and Gastroenterology, Helios-Klinikum Berlin-Buch, 13125 Berlin, Germany * Correspondence: trojan@em.uni-frankfurt.de; Tel.: +49-69-6301-7860; Fax: +49-69-6301-83776

Simple Summary: Transarterial chemoembolization (TACE) is the treatment of choice for patients with liver cancer without distant metastases or tumor growth into blood vessels. For the latter patients, sorafenib is a well-established oral medication. Combination of both treatments might also enhance effectiveness and survival in patients with advanced tumor stages. We retrospectively compared patients with advanced liver cancer (with distant metastases and/or tumor growth into blood vessels) from three German university hospitals who received either TACE alone, sorafenib alone or the combination treatment. We found that survival was prolonged for patients receiving the combination treatment without increasing frequency or severity of side effects. These results are in line with published results from Asian patients and show that this treatment might also be feasible in a Western population for selected patients with advanced liver cancer.

Abstract: Background and Aims. Systemic treatment with sorafenib has been the standard of care (SOC) in patients with advanced Barcelona Clinic Liver Cancer (BCLC) stage C hepatocellular carcinoma (HCC) for more than a decade. TACE has been reported to allow better local tumor control in selected patients with BCLC stage C HCC. Methods. A retrospective analysis of patients with BCLC stage C HCC that were treated with sorafenib and TACE was conducted; they were compared to BCLC stage $C$ patients treated either with TACE or sorafenib in the same period of time outside a clinical trial. Results. A total of 201 patients with BCLC stage $C$ were identified, who were treated with either sorafenib and TACE (group A; $n=54$ ), sorafenib (group B; $n=82$ ) or TACE (group $C ; n=65)$. No significant difference in baseline characteristics was observed. Time to progression was 7.0 months (95\% CI: 4.3-9.7), 4.1 months (95\% CI: 3.6-4.7) and 5.0 months (95\% CI: 2.9-7.1) in groups A, B and C, respectively, and overall survival was 16.5 months (95\% CI: 15.0-18.1), 8.4 months (95\% CI: 6.0-10.8) and 10.5 months (95\% CI: 7.5-13.6), respectively (group A vs. group B: $p<0.001$; 
group A vs. group C: $p=0.0023$ ). Adverse events of grade $3 / 4$ occurred in $34 \%$ of patients in group A. Conclusions. Although sorafenib is a SOC in patients with BCLC stage C HCC, TACE is frequently used as an additional locoregional treatment in selected patients. This combined approach resulted in a significant overall survival benefit in selected patients, although randomized trials have not yet proven this benefit.

Keywords: HCC; TACE; sorafenib; treatment

\section{Introduction}

The worldwide incidence of hepatocellular carcinoma (HCC) is rising, with an annual incidence of above 600,000 patients [1]. Treatment of HCC is challenging because HCC mainly occurs within liver cirrhosis, and therapeutic options and prognosis are determined by tumor biology as well as impaired liver function [2]. Currently, the most commonly used clinical staging system in Western countries is the Barcelona Clinic Liver Cancer (BCLC) algorithm $[3,4]$. According to BCLC, treatment is stratified depending on tumor stage, liver function and performance status. Intermediate-stage HCC (BCLC stage B) without options for surgical treatment or ablation is best treated by transarterial chemoembolization (TACE), which has been shown to extend median survival from 16 to 20 months [5,6]. Response rates after TACE treatment are in the range of about 35\% [6,7]. Advanced-stage HCC (BCLC stage $\mathrm{C}$ ) is defined by portal vein infiltration (PVI), extrahepatic tumor manifestation (EHM) and/or a reduced Eastern Cooperative Group (ECOG) performance status. In patients with $B C L C$ stage $C$, treatment with sorafenib, an oral multi-tyrosine kinase and angiogenesis inhibitor with activity against vascular endothelial growth factor receptor (VEGFR)-2, PDGFR, c-Kit receptors, BRAF and p38 signal transduction pathways, was considered the standard of care (SOC) at the time the study was conducted. Two independent pivotal phase 3 trials demonstrated a survival benefit compared to a placebo in Caucasian and Asian patients with HCC $[8,9]$. Prognosis in advanced-stage HCC is strongly dependent on the preservation of liver function, and the majority of patients with BCLC stage C die because of either liver failure or intrahepatic progression $[10,11]$. Since TACE is also feasible in patients with side-branch PVI, some investigators achieved overall survival rates comparable to treatment with sorafenib in selected patients with HCC BCLC stage C $[12,13]$. Treatment with TACE leads to vascular endothelial growth factor (VEGF) upregulation in HCC patients [14]. Since sorafenib also targets VEGF [15], a combination of sorafenib as an inhibitory factor with TACE might decrease neovascularization and, therefore, potentiate the effect of chemoembolization, though this has never been shown in a randomized trial in BCLC stage B patients thus far for several possible reasons, including the high technical variability between different liver centers. However, two reports from China suggest that the combination of sorafenib and TACE in advanced HCC is also feasible, and the efficacy is encouraging $[16,17]$. To compare the efficacy of the combination of sorafenib and TACE to either TACE alone or sorafenib alone in Western HCC patients, a retrospective cohort study was initiated at three German liver centers.

\section{Patients and Methods}

Between January 2007 and December 2012, a consecutive cohort of HCC patients treated with sorafenib in combination with TACE (group A) at three German liver centers (Goethe-University, Frankfurt; Charité, Berlin and Ludwig Maximilians University, Munich) was studied retrospectively. Additionally, patients with advanced-stage HCC treated with either sorafenib (group B) or TACE (group C) in the same period of time were included. HCC was diagnosed according to the criteria published by the European Association for the Study of Liver Disease/American Association for the Study of Liver Disease [5]. Inclusion criteria for the study population were as follows: ECOG performance status $\leq 2$, ChildPugh class A or B (scores $\leq 8)$ and BCLC stage C. Only patients treated with sorafenib for 
a minimum of 30 days were considered. Other, e.g., loco-regional, treatments or resection in the medical history were allowed. Patients with progression from BCLC stage B to stage $C$ while receiving TACE treatment were excluded. Complete in- and exclusion criteria are listed in Supplementary File S1. In group A, TACE was usually initiated before sorafenib. The applied conventional lipiodol-based TACE protocols at the three centers used either mitomycin $\mathrm{C}$, epirubicin or doxorubicin as chemotherapeutic agents and were repeated every 4-8 weeks and terminated in case of either progression, toxicity or complete tumor devascularization. After the start of sorafenib treatment, patients were initially closely followed for 7-14 days and every 4-8 weeks thereafter, as appropriate. Intervals between radiological examinations were usually ten to twelve weeks. Overall survival and time to radiological progression were analyzed at all three centers, whereas adverse events were analyzed in detail in Frankfurt only. The ethics committee at the Goethe-University Hospital Frankfurt, Germany, approved the study.

\section{Statistical Analyses}

Statistical analyses were carried out using BiAs 10.03 software (Frankfurt, Germany) and Microsoft Office Excel 2007 (Microsoft Corporation, Redmont, WA, USA).

Patients with CLIP score $>4$ points and Child-Pugh score $>8$ were excluded from the analysis. In total, 201 patients were included in the final analysis. Continuous parameters were analyzed with descriptive methods (mean with standard deviation); the KruskalWallis test was used for comparison of different groups. Categorical parameters were expressed as frequency and percentages and analyzed using Fisher's exact test. Survival was calculated from the date of first TACE treatment or the day of first sorafenib dose until data closure, loss to follow-up or death, whichever came first. Median survival times and median times to radiological progression were analyzed with the Kaplan-Meier method and log-rank test; $p$-values $<0.05$ were considered statistically significant. Uniand multivariate analyses were carried out to identify prognostic predictors for survival time using Cox regression and log-rank tests, $p$-values $<0.05$ were considered statistically significant.

\section{Results}

\subsection{Patients}

In total, 54, 82 and 65 patients were included in groups A-C, respectively (Figure 1). There was no significant difference in baseline characteristics between the three groups (Table 1).

Table 1. Patient characteristics.

\begin{tabular}{|c|c|c|c|c|}
\hline $\begin{array}{c}\text { Patients' }^{\prime} \\
\text { Characteristics }\end{array}$ & $\begin{array}{c}\text { Sorafenib/TACE } \\
\text { (Group A) } \\
n=54\end{array}$ & $\begin{array}{c}\text { Sorafenib } \\
\text { (Group B) } \\
n=82\end{array}$ & $\begin{array}{c}\text { TACE } \\
\text { (Group C) } \\
n=65\end{array}$ & $p$-Value \\
\hline Median age (range) & $\begin{array}{c}64.0 \\
(34-77)\end{array}$ & $\begin{array}{c}65.9 \\
(28-85)\end{array}$ & $\begin{array}{c}67.0 \\
(41-80)\end{array}$ & 0.13 \\
\hline Male sex & $87 \%$ & $88 \%$ & $82 \%$ & 0.56 \\
\hline Alcohol abuse & $31 \%$ & $28 \%$ & $38 \%$ & 0.41 \\
\hline Viral hepatitis & $43 \%$ & $35 \%$ & $34 \%$ & 0.56 \\
\hline NASH & $7 \%$ & $6 \%$ & $8 \%$ & 0.88 \\
\hline Cryptogenic/other causes & $19 \%$ & $31 \%$ & $20 \%$ & 0.21 \\
\hline BCLC stage C & $100 \%$ & $100 \%$ & $100 \%$ & 1.0 \\
\hline Child-Pugh A & $74 \%$ & $74 \%$ & $77 \%$ & 0.94 \\
\hline Child-Pugh B & $26 \%$ & $26 \%$ & $23 \%$ & \\
\hline ECOG PS $\geq 1$ & $70 \%$ & $55 \%$ & $62 \%$ & 0.19 \\
\hline
\end{tabular}


Table 1. Cont.

\begin{tabular}{|c|c|c|c|c|}
\hline $\begin{array}{c}\text { Patients' }^{\prime} \\
\text { Characteristics }\end{array}$ & $\begin{array}{c}\text { Sorafenib/TACE } \\
\text { (Group A) } \\
n=54\end{array}$ & $\begin{array}{c}\text { Sorafenib } \\
\text { (Group B) } \\
\quad n=82\end{array}$ & $\begin{array}{c}\text { TACE } \\
\text { (Group C) } \\
n=65\end{array}$ & $p$-Value \\
\hline $\begin{array}{l}\text { Tumor burden } \\
\geq 50 \% \text { liver involvement }\end{array}$ & $15 \%$ & $22 \%$ & $15 \%$ & 0.86 \\
\hline Portal vein infiltration (grade 1-3) & $33 \%$ & $33 \%$ & $38 \%$ & 0.77 \\
\hline Extrahepatic spread & $41 \%$ & $46 \%$ & $34 \%$ & 0.31 \\
\hline $\begin{array}{l}\alpha \text {-Fetoprotein } \\
\geq 400 \mathrm{ng} / \mathrm{dL}\end{array}$ & $34 \%$ & $36 \%$ & $38 \%$ & 0.89 \\
\hline $\begin{array}{l}\text { CLIP score } \\
\text { (range) }\end{array}$ & $\begin{array}{l}2.1 \pm 1.0 \\
(1.0-4.0)\end{array}$ & $\begin{array}{l}2.1 \pm 0.8 \\
(1.0-4.0)\end{array}$ & $\begin{array}{l}2.1 \pm 0.8 \\
(1.0-4.0)\end{array}$ & \\
\hline
\end{tabular}

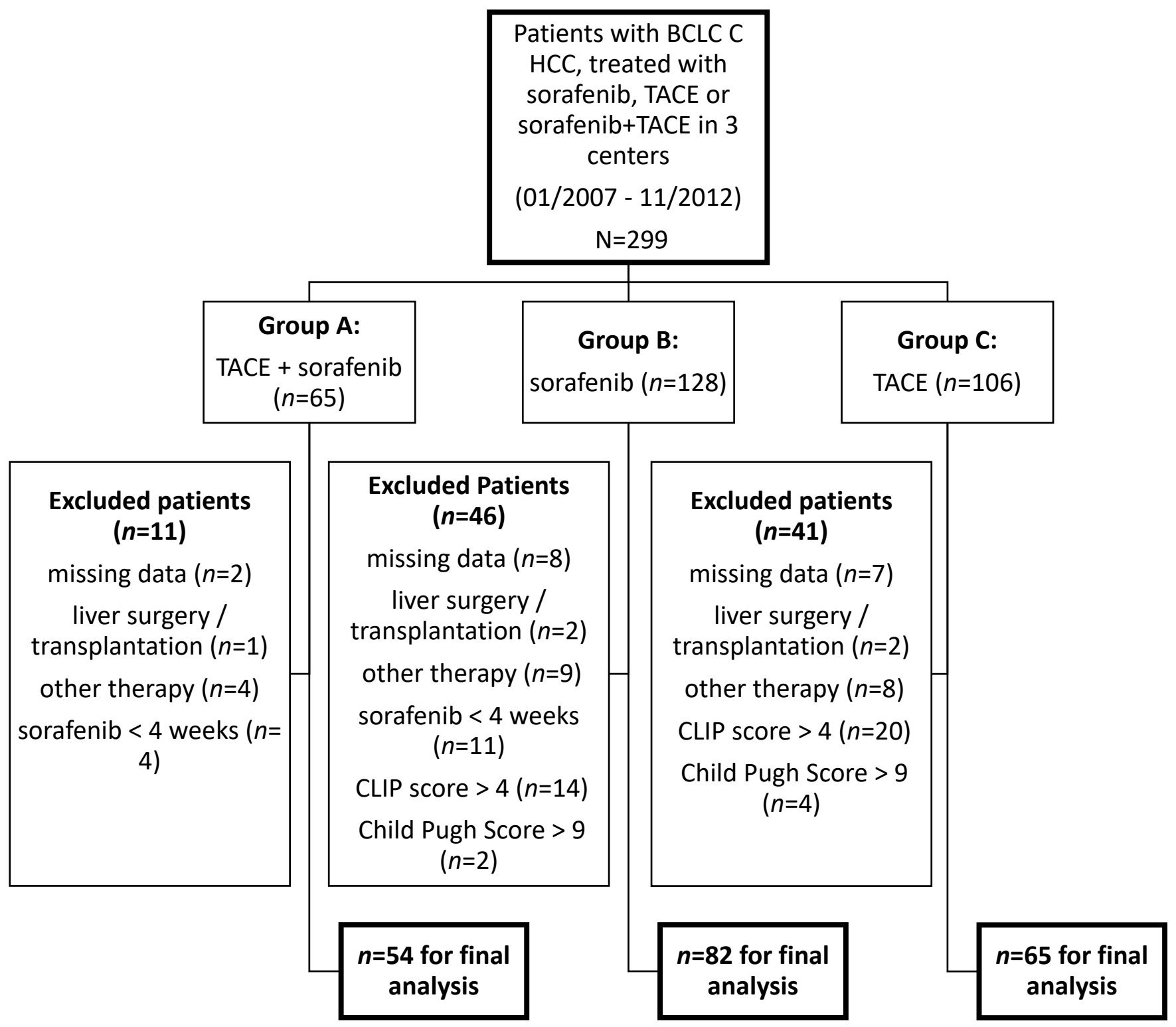

Figure 1. Patient characteristics. 


\subsection{Radiologic Response}

Based on the RECIST 1.1 tumor evaluation, the median time to radiological progression (TTP) was 7.0 months (95\% CI: 4.3-9.7), 4.1 months (95\% CI: 3.6-4.7) and 5.0 months (95\% CI: 2.9-7.1) in groups A, B and C, respectively (Figure 2). The TTP in patients in the combination arm was significantly longer than that in groups $B$ and $C$ (group A vs. group B: $p<0.001$; group A vs. group C: $p<0.001$ ).

Radiological evaluation after six months showed significantly higher disease control and objective response rates in the combination group as compared to the single-treatment groups: the DCR was 53\% in the sorafenib/TACE group as compared to $23 \%$ in the sorafenib group and $38 \%$ in the TACE group ( $p=0.0024)$; the ORR was $15 \%$ in the combination group, $3 \%$ in the sorafenib group and $9 \%$ in the TACE group $(p=0.019)$ (Table 2$)$.

Table 2. Summary of outcomes according to RECIST 1.1 evaluation after 6 months.

\begin{tabular}{ccccc}
\hline $\begin{array}{c}\text { 6-Month Radiologic Evaluation } \\
\text { (RECIST 1.1) }\end{array}$ & $\begin{array}{c}\text { Sorafenib/TACE } \\
(\boldsymbol{n}=\mathbf{5 3}) *\end{array}$ & $\begin{array}{c}\text { Sorafenib } \\
(\boldsymbol{n}=\mathbf{7 4}) *\end{array}$ & $\begin{array}{c}\text { TACE } \\
(\boldsymbol{n}=\mathbf{5 8})\end{array}$ & $\boldsymbol{p}$-Value \\
Complete response & $0(0 \%)$ & $0(0 \%)$ & $0(0 \%)$ & 1.0 \\
Partial response & $8(15 \%)$ & $2(3 \%)$ & $5(9 \%)$ & 0.0187 \\
Stable disease & $20(38 \%)$ & $15(20 \%)$ & $17(29 \%)$ & 0.1423 \\
Progression of disease $_{\text {Disease control rate }}^{ \pm}$ & $25(47 \%)$ & $57(77 \%)$ & $36(62 \%)$ & 0.0024 \\
Objective response rate $^{\mathbb{I I}}$ & $28(53 \%)$ & $17(23 \%)$ & $22(38 \%)$ & 0.0024 \\
\hline
\end{tabular}

${ }^{*}$ One patient had missing data; ${ }^{ \pm}$Calculated as CR + PR + SD; II Calculated as CR + PR.

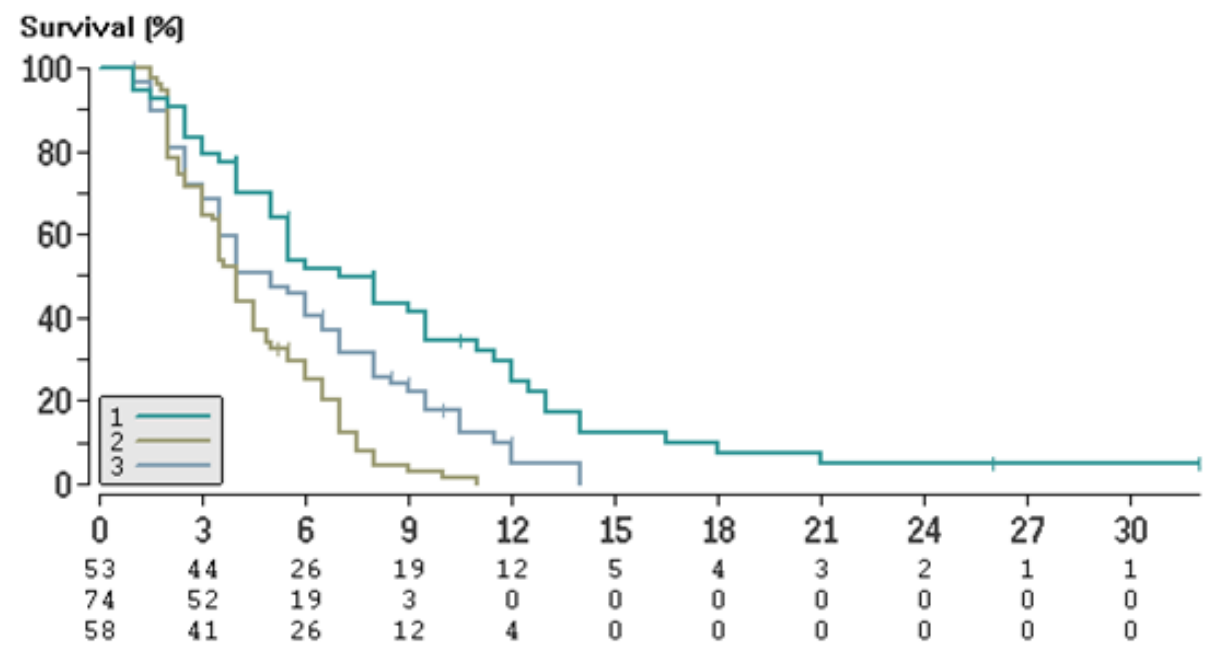

Kaplan-Meier-analysis for time to radiological progression; 1: sorafenib/TACE, 2: sorafenib; 3: TACE

Figure 2. Time to radiological progression.

\subsection{Survival Times}

Median overall survival (OS) was 16.5 months (95\% CI: 15.0-18.1), 8.4 months (95\% CI: 6.0-10.8) and 10.5 months (95\% CI: 7.5-13.6) in groups A, B and C, respectively (Figure 3, Table 3). The OS in patients in the combination arm was significantly longer than that in groups B and C (group A vs. group B: $p<0.001$; group A vs. group C: $p=0.0023$ ). Until the end of follow-up (November 2012), 61\% of patients in the sorafenib and TACE group, $81 \%$ of patients in the sorafenib group and $79 \%$ of patients in the TACE group had died. There was no significant difference between patients with or without distant metastases in the individual groups (group A: $p=0.59$; group $\mathrm{B}: p=0.27$; group $\mathrm{C}: p=0.99$ ). 


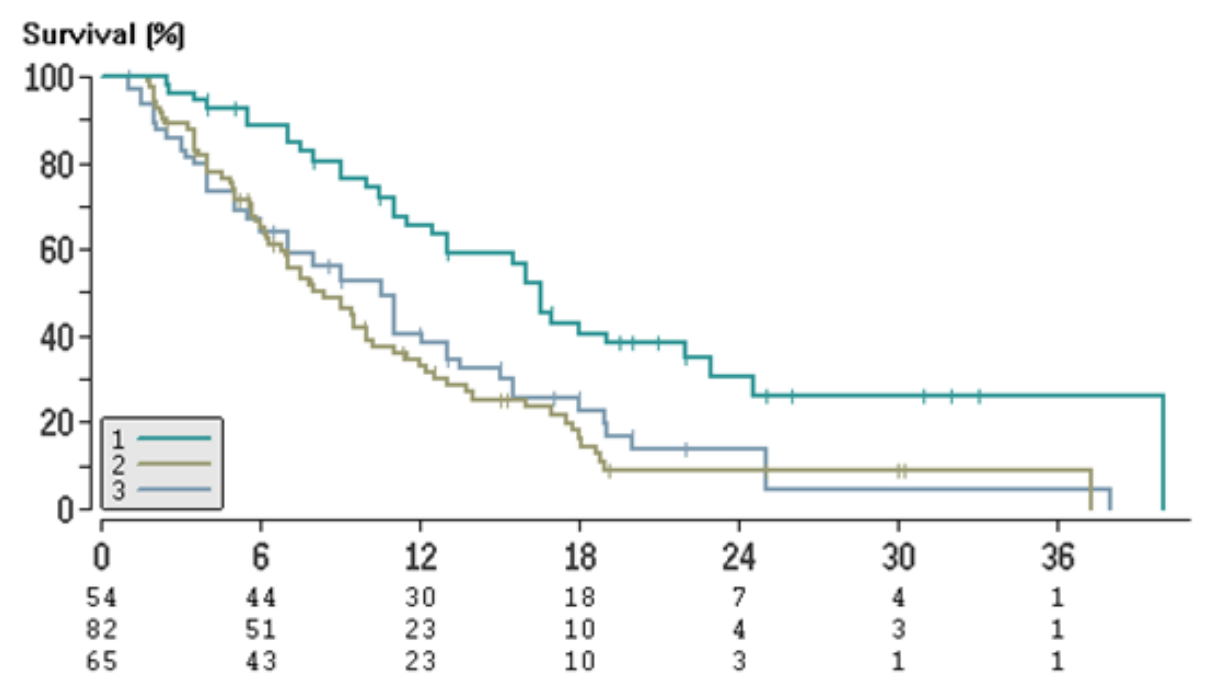

Kaplan-Meier-analysis for overall survival; 1: sorafenib/TACE, 2: sorafenib; 3: TACE

Figure 3. Overall survival.

Table 3. Survival according to treatment.

\begin{tabular}{ccccc}
\hline Treatment Group & $\begin{array}{c}\text { mOS } \\
\text { (Months) }\end{array}$ & $\begin{array}{c}\text { 1-Year Survival } \\
\text { Rate (\%) }\end{array}$ & $\begin{array}{c}\text { 2-Year Survival } \\
\text { Rate (\%) }\end{array}$ & $\begin{array}{c}\text { Survival at } \\
\text { Data Closure (\%) }\end{array}$ \\
\hline Group A: all patients & 16.5 & $56 \%$ & $13 \%$ & $39 \%$ \\
liver only & 16.1 & & & \\
metastases & 19.0 & $28 \%$ & $5 \%$ & \\
\hline Group B: all patients & 8.4 & & & \\
liver only & 8.4 & $37 \%$ & $6 \%$ & \\
metastases & 7.5 & & & \\
\hline Group C: all patients & 10.5 & & & \\
liver only & 10.5 & $38 \%$ & & \\
metastases & 10.5 & 11.0 & & \\
\hline All patients & & & & \\
\hline
\end{tabular}

In the multivariate analysis, a baseline Child-Pugh score B (HR 0.47), ECOG status $\geq$ 1 (HR 0.56) and alpha-fetoprotein level >400 ng/dL (HR 0.56) were negative predictors of survival (Table 4).

Table 4. Multivariate analysis of predictors for survival.

\begin{tabular}{cccc}
\hline Predictor & HR & $\mathbf{9 5 \% ~ C I ~}$ & $p$-Value \\
\hline Sorafenib/TACE & 0.34 & $0.23-0.53$ & $<\mathbf{0 . 0 0 1}$ \\
Child-Pugh score & 0.48 & $0.31-0.71$ & $<\mathbf{0 . 0 0 1}$ \\
ECOG PS & 0.56 & $0.37-0.83$ & $\mathbf{0 . 0 0 2}$ \\
AFP $\geq$ 400 ng/mL & 1.79 & $1.25-2.5$ & $\mathbf{0 . 0 0 6}$ \\
CLIP score 1-2 & 0.91 & $0.56-1.42$ & 0.68 \\
Zhao risk score $<11.5$ & 0.87 & $0.56-1.42$ & 0.53 \\
\hline
\end{tabular}

Bold to illustrate significant $p$ values.

Sorafenib-related adverse events were comparable in patients in the sorafenib/TACE group as compared to patients who received only sorafenib treatment (Table 5). A dose reduction of sorafenib was documented in $66 \%$ of patients in the combination group and in $60 \%$ in the sorafenib group. Adverse events in patients in the TACE group are listed in 
Table 6 and were also not significantly different between the TACE-only and combination treatment patients.

Table 5. Sorafenib-related adverse events.

\begin{tabular}{ccc}
\hline Adverse events & $\begin{array}{c}\text { Sorafenib/TACE } \\
\text { (Group A) } \\
n=50\end{array}$ & $\begin{array}{c}\text { Sorafenib } \\
\text { (Group B) } \\
n=78\end{array}$ \\
\hline Any adverse event & $86 \%$ & $80 \%$ \\
\hline Adverse events $\geq$ grade 3 & $34 \%$ & $32 \%$ \\
\hline Sorafenib dose reduction & $66 \%$ & $60 \%$ \\
Diarrhea & $26 \%$ & $22 \%$ \\
Hand-foot skin reaction & $24 \%$ & $17 \%$ \\
Fatigue & $6 \%$ & $8 \%$ \\
\hline Sorafenib interruption & $38 \%$ & $35 \%$ \\
Hand-foot skin reaction & $12 \%$ & $10 \%$ \\
Diarrhea & $10 \%$ & $10 \%$ \\
Fatigue & $6 \%$ & $5 \%$ \\
\hline Termination of sorafenib & $12 \%$ & $15 \%$ \\
Hand-foot skin reaction & $4 \%$ & $4 \%$ \\
Diarrhea & $2 \%$ & $3 \%$
\end{tabular}

Table 6. Adverse events related to TACE occurring in $\geq 10 \%$ of the patients.

\begin{tabular}{ccc}
\hline Adverse Events, $\mathbf{n}(\boldsymbol{\%})$ & $\begin{array}{c}\text { Sorafenib + TACE } \\
(\boldsymbol{n}=\mathbf{3 7 )}\end{array}$ & $\begin{array}{c}\text { TACE } \\
(\boldsymbol{n}=\mathbf{3 8})\end{array}$ \\
\hline Postembolization syndrome * & $11(30 \%)$ & $13(34 \%)$ \\
Abdominal pain & $14(41 \%)$ & $17(45 \%)$ \\
Nausea & $12(33 \%)$ & $13(34 \%)$ \\
Fever in absence of infection & $10(27 \%)$ & $10(26 \%)$ \\
Vomiting & $5(14 \%)$ & $6(16 \%)$ \\
New ascites & $9(24 \%)$ & $8(21 \%)$ \\
Fatigue & $8(22 \%)$ & $5(13 \%)$ \\
Liver dysfunction & $6(16 \%)$ & $4(11 \%)$ \\
Anorexia & $5(14 \%)$ & $4(11 \%)$ \\
\hline
\end{tabular}

* Postembolization syndrome did not require prolonged hospitalization (beyond $24 \mathrm{~h}$ ) for post-treatment observation.

\section{Discussion}

In this multi-center, retrospective cohort study, we evaluated the efficacy and safety of sorafenib in combination with TACE in patients with advanced HCC.

We found that the combination treatment significantly prolonged the time to radiological progression, disease control and overall response rate as well as the median overall survival. Adverse events did not occur more frequently in these patients when compared to the patients receiving sorafenib or TACE only. Since all groups were well balanced, those differences cannot be attributed to differences in liver function or tumor burden. Nevertheless, due to the retrospective nature of the study, a selection bias cannot be excluded. Additionally, the technical aspect is important for interpretation of our data and the reports in the literature: TACE protocols and the technical performance of the interventional radiologist naturally differ between departments. Therefore, small groups of highly selected patients might show a benefit that probably cannot be generalized. We also did not analyze salvage treatments separately, although they might have influenced survival times.

It has been suggested that only patients with tumors without vascular invasion or extrahepatic spread (BCLC stage B) benefit from TACE [3]. However, in everyday practice, TACE is also applied in selected patients with advanced HCC to enhance local tumor control $[18,19]$ and also in patients with grade 1 or 2 thromboses of the portal vein [20]. 
Clinical studies investigating the prognostic role of extrahepatic spread in HCC patients that were treated with sorafenib returned conflicting results. However, in a recent trial by Schütte et al., prognosis of HCC patients treated with a combination of SIRT and sorafenib depended mainly on the extent of liver involvement [21]. In our trial, patients with or without extrahepatic metastases did not show significant differences in their median survival. In our opinion, this justifies the selection of the criterion of BCLC stage over extrahepatic spread or different subgroups according to tumor size.

The SPACE trial, studying the effect of sorafenib in combination with doxorubicineluting beads and TACE in intermediate-stage HCC (BCLC stage B), showed no relevant benefit with the addition of sorafenib [22]. In our cohort with only BCLC stage C patients, every center used their preferred TACE regimen, which was, in the majority of procedures, a canonical, lipiodol-based TACE. Moreover, sorafenib dose adjustments were frequently documented. Of note, sorafenib-related adverse events were comparable in patients treated with sorafenib in combination with TACE compared to sorafenib alone. Liu et al. retrospectively compared patients with BCLC stage C HCC that received TACE and sorafenib vs. patients treated with TACE alone. They confirmed our results of a better local tumor control and longer survival for the combination group. The median OS and survival rate of the TACE monotherapy group at one year in our trial were slightly higher than those reported by Liu et al. Lee et al. analyzed patients receiving either TACE alone or in combination with sorafenib, and the survival times in the monotherapy group were shorter than those in our cohort. These differences have to be interpreted with caution, however, due to the high clinical variability of BCLC stage C patients [23,24]. Varghese et al. also analyzed a mixed dataset of BCLC stage B and C patients and found a survival benefit of the combination treatment at both stages [25]. Additionally, a recent prospective trial by Kudo et al. (TACTICS) stressed the effect of a combination treatment on local tumor control, although only a minority of patients suffered from BCLC stage C HCC [26]. Taken together, the combination treatment with TACE and sorafenib seems to be feasible and safe in BCLC stage $C$ patients. Zhao et al. proposed [17] a risk score to further divide BCLC stage $C$ patients into subgroups according to vascular invasion, Child-Pugh stage and tumor burden. Patients with a score of less than 11.5 should receive the combination treatment. Our trial adds value to the current knowledge by proving the treatment's safety and feasibility in Western patients.

The patients in our study were included retrospectively and according to in- and exclusion criteria as mentioned above. Therefore, there were no major differences over the course of six years. Until the approval of lenvatinib as additional first line treatment in HCC patients in 2018, sorafenib was the only systemic treatment in HCC patients. No other (further-line) options, such as cabozantinib, regorafenib and ramucirumab as well as atezolizumab/bevacizumab, were available at the time the study was conducted and, therefore, did not influence survival analyses.

In 2018, the tyrosine kinase inhibitor lenvatinib was approved by the FDA and the EMA as an alternative first-line treatment for patients with advanced HCC, following the results of a phase III non-inferiority trial that compared sorafenib and lenvatinib in this indication [27]. One recent retrospective study investigated the combination treatment of TACE and lenvatinib in a Japanese cohort and found a survival benefit for patients when treated alternatingly [28]. The most recent development in HCC treatment was the approval of atezolizumab and bevacizumab in patients with advanced HCC in 2020 after the results of the pivotal IMbrave150 trial, which is considered as the new SOC in advanced HCC [29]. Nevertheless, the role of combined locoregional therapy and systemic therapy is being further studied, also in combination with immunotherapy NCT04803994, NCT04340193) [30]. Since advanced HCC is a very heterogenous disease as defined by BCLC and other staging systems, it is challenging to run international multi-center studies using a combination of locoregional therapy together with systemic therapy. 


\title{
6. Conclusions
}

In conclusion, the results of our retrospective cohort study at three Western HCC centers indicate that carefully selected Western HCC patients might also benefit from a combination approach using TACE and the TKI sorafenib, although randomized trials have not yet proven this.

Supplementary Materials: The following are available online at https:/ /www.mdpi.com/article/10 $.3390 /$ cancers13092121/s1, File S1: Inclusion criteria and exclusion criteria.

Author Contributions: Conceptualization, J.T., M.G., E.S., O.W. and F.T.K.; validation, M.G., C.K.; formal analysis, M.G., C.K.; investigation, M.G., M.o.d.W., J.T.; resources, E.S., P.P., S.Z. (Stephan Zangos), S.Z. (Stefan Zeuzem), T.V., W.O.B., F.T.K.; data curation, M.G., M.o.d.W.; writing_original draft preparation, C.K., J.T.; writing—review and editing, C.K., M.G., E.S., M.o.d.W., F.T.K., S.Z. (Stephan Zangos), S.Z. (Stefan Zeuzem), J.T., O.W., P.P., T.V., W.O.B.; visualization, M.G., C.K.; supervision, J.T.; project administration, J.T.; All authors have read and agreed to the published version of the manuscript."

Funding: This research received no external funding.

Institutional Review Board Statement: The study was conducted according to the guidelines of the Declaration of Helsinki, and approved by the Ethics Committee of Frankfurt University Clinic (protocol code 4/09, 22 January 2009).

Informed Consent Statement: Informed consent was obtained from all subjects involved in the study.

Data Availability Statement: The data presented in this study are available on request from the corresponding author. The data are not publicly available due to ethical restrictions.

Acknowledgments: The authors would like to thank Katharina Fischer for help with data acquisition.

Conflicts of Interest: C. Koch received honoraria for talks and advisory board role from Merck Sharp \& Dome, Eisai, Ipsen, Novartis/AAA, Roche, Bayer, Elsevier and Servier. She received travel support from Ipsen and Medac. O. Waidmann received honoraria for talks and advisory board role from AstraZeneca, Amgen, Bayer, BMS, Celegene, Eisai, Incyte, Ipsen, Merck Serono, MSD, Novartis, Roche, Servier and Shire. He received travel support from Abbvie, Bayer, BMS, Gilead, Ipsen, Medac, and Merck Serono and received grants for investigator-initiated trials from the Else Kröner-Fresenius-Stiftung, Medac and Merck Serono. He is an investigator for Basilea, Incyte and MSD. E. Schott, S. Zeuzem and F.T. Kolligs received consulting and/or lecture fees from Bayer Health Care. J. Trojan received honoraria for talks and advisory board role from Amgen, Astra Zeneca, Bayer Healthcare, Bristol Myers-Squibb, Eisai, Ipsen, Merck Serono, Merck Sharp \& Dome, Lilly Imclone, Roche and Servier. He received research funding from Ipsen and Roche. M. op den Winkel received lecture fees from Falk Foundation. The other authors declare no conflict of interests.

\begin{abstract}
Abbreviations
HCC, hepatocellular carcinoma; BCLC, Barcelona Clinic Liver Cancer; DCR, disease control rate, SOC, standard of care; TACE, transarterial chemoembolization; PVI, portal vein infiltration; EHM, extrahepatic tumor manifestation; ECOG, Eastern Cooperative Group; SOC, standard of care; VEGFR, vascular growth factor receptor; $\mathrm{CR}$, complete response; $\mathrm{ORR}$; overall response rate; $\mathrm{OS}$, overall survival; $\mathrm{PFS}$, progression free survival; $\mathrm{PR}$, partial remission; $\mathrm{SD}$, stable disease; $\mathrm{PD}$, progressive disease.
\end{abstract}

\section{References}

1. Jemal, A.; Bray, F.; Center, M.M.; Ferlay, J.; Ward, E.; Forman, D. Global cancer statistics. CA Cancer J. Clin. 2011, 61, 69-90. Available online: https://pubmed.ncbi.nlm.nih.gov/21296855/ (accessed on 20 November 2020). [CrossRef]

2. $\quad$ El-Serag, H.B. Hepatocellular Carcinoma. N. Engl. J. Med. 2011, 365, 1118-1127. [CrossRef]

3. Llovet, J.M.; Brú, C.; Bruix, J. Prognosis of hepatocellular carcinoma: The BCLC staging classification. Semin. Liver Dis. 1999, 19, 329-337. Available online: https:/ / pubmed.ncbi.nlm.nih.gov/10518312/ (accessed on 20 November 2020). [CrossRef] [PubMed]

4. Bruix, J.; Sherman, M. Management of hepatocellular carcinoma: An update. Hepatology 2011, 53, 1020-1022. Available online: https://pubmed.ncbi.nlm.nih.gov/21374666/ (accessed on 20 November 2020). [CrossRef] [PubMed] 
5. Llovet, J.M.; Ducreux, M.; Lencioni, R.; Di Bisceglie, A.; Galle, P.; Dufour, J. European Association for the Study of the Liver: European Organisation for Research and Treatment of Cancer. EASL-EORTC clinical practice guidelines: Management of hepatocellular carcinoma. J. Hepatol. 2012, 56, 908-943.

6. Llovet, J.M.; Bruix, J. Systematic review of randomized trials for unresectable hepatocellular carcinoma: Chemoembolization improves survival. Hepatology 2003, 37, 429-442. Available online: https:/ / pubmed.ncbi.nlm.nih.gov/12540794/ (accessed on 20 November 2020). [CrossRef]

7. Han, G.; Berhane, S.; Toyoda, H.; Bettinger, D.; Elshaarawy, O.; Chan, A.W.; Kirstein, M.; Mosconi, C.; Hucke, F.; Palmer, D.; et al. Prediction of Survival Among Patients Receiving Transarterial Chemoembolization for Hepatocellular Carcinoma: A Response-Based Approach. Hepatology 2020, 72, 198-212. [CrossRef] [PubMed]

8. Llovet, J.M.; Ricci, S.; Mazzaferro, V.; Hilgard, P.; Gane, E.; Blanc, J.F.; De Oliveira, A.C.; Santoro, A.; Raoul, J.L.; Forner, A.; et al. Sorafenib in Advanced Hepatocellular Carcinoma. N. Engl. J. Med. 2008, 359, 378-390. Available online: https: / / pubmed.ncbi.nlm.nih.gov/18650514/ (accessed on 20 November 2020). [CrossRef]

9. Cheng, A.L.; Kang, Y.K.; Chen, Z.; Tsao, C.J.; Qin, S.; Kim, J.S.; Luo, R.; Feng, J.; Ye, S.; Yang, T.S.; et al. Efficacy and safety of sorafenib in patients in the Asia-Pacific region with advanced hepatocellular carcinoma: A phase III randomised, double-blind, placebo-controlled trial. Lancet Oncol. 2009, 10, 25-34. [CrossRef]

10. Uka, K.; Aikata, H.; Takaki, S.; Shirakawa, H.; Jeong, S.C.; Yamashina, K.; Hiramatsu, A.; Kodama, H.; Takahashi, S.; Chayama, K. Clinical features and prognosis of patients with extrahepatic metastases from hepatocellular carcinoma. World J. Gastroenterol. 2007, 13, 414-420. Available online: https:/ / pubmed.ncbi.nlm.nih.gov/17230611/ (accessed on 20 November 2020). [CrossRef]

11. Yoo, D.J.; Kim, K.M.; Jin, Y.J.; Shim, J.H.; Ko, G.Y.; Yoon, H.K.; Sung, K.B.; Lee, J.L.; Kang, Y.K.; Lim, Y.S.; et al. Clinical outcome of 251 patients with extrahepatic metastasis at initial diagnosis of hepatocellular carcinoma: Does transarterial chemoembolization improve survival in these patients? J. Gastroenterol. Hepatol. 2011, 26, 145-154. Available online: https:// pubmed.ncbi.nlm.nih. gov /21175808/ (accessed on 20 November 2020). [CrossRef]

12. Pinter, M.; Hucke, F.; Graziadei, I.; Vogel, W.; Maieron, A.; Königsberg, R.; Stauber, R.; Grünberger, B.; Müller, C.; Kölblinger, C.; et al. Advanced-stage hepatocellular carcinoma: Transarterial chemoembolization versus sorafenib. Radiology 2012, 263, 590-599. Available online: https:/ / pubmed.ncbi.nlm.nih.gov/22438359/ (accessed on 20 November 2020). [CrossRef] [PubMed]

13. Georgiades, C.S.; Hong, K.; D'Angelo, M.; Geschwind, J.F.H. Safety and efficacy of transarterial chemoembolization in patients with unresectable hepatocellular carcinoma and portal vein thrombosis. J. Vasc. Interv. Radiol. 2005, 16, 1653-1659. Available online: https: / / pubmed.ncbi.nlm.nih.gov/16371532/ (accessed on 20 November 2020). [CrossRef]

14. Schicho, A.; Hellerbrand, C.; Krüger, K.; Beyer, L.P.; Wohlgemuth, W.; Niessen, C.; Hohenstein, E.; Stroszczynski, C.; Pereira, P.L.; Wiggermann, P. Impact of different embolic agents for transarterial chemoembolization (TACE) procedures on systemic vascular endothelial growth factor (VEGF) levels. J. Clin. Transl. Hepatol. 2016, 4, 288-292. Available online: https://pubmed.ncbi.nlm.nih. gov /28097096/ (accessed on 17 April 2021). [PubMed]

15. Greten, T.F.; Korangy, F.; Manns, M.P.; Malek, N.P. Molecular therapy for the treatment of hepatocellular carcinoma. Br. J. Cancer 2009, 100, 19-23. Available online: https:/ / pubmed.ncbi.nlm.nih.gov/19018262/ (accessed on 17 April 2021). [CrossRef]

16. Bai, W.; Wang, Y.J.; Zhao, Y.; Qi, X.S.; Yin, Z.X.; He, C.Y.; Li, R.J.; Wu, K.C.; Xia, J.L.; Fan, D.M.; et al. Sorafenib in combination with transarterial chemoembolization improves the survival of patients with unresectable hepatocellular carcinoma: A propensity score matching study. J. Dig. Dis. 2013, 14, 181-190. Available online: https:// pubmed.ncbi.nlm.nih.gov/23324079/ (accessed on 20 November 2020). [CrossRef]

17. Zhao, Y.; Wang, W.J.; Guan, S.; Li, H.L.; Xu, R.C.; Wu, J.B.; Liu, J.S.; Li, H.P.; Bai, W.; Yin, Z.X.; et al. Sorafenib combined with transarterial chemoembolization for the treatment of advanced hepatocellular carcinoma: A large-scale multicenter study of 222 patients. Ann. Oncol. 2013, 24, 1786-1792. Available online: http://www.ncbi.nlm.nih.gov/pubmed/23508822 (accessed on 18 June 2019). [CrossRef]

18. Galle, P.R.; Forner, A.; Llovet, J.M.; Mazzaferro, V.; Piscaglia, F.; Raoul, J.L.; Schirmacher, P.; Vilgrain, V. EASL Clinical Practice Guidelines: Management of hepatocellular carcinoma. J. Hepatol. 2018, 69, 182-236. [CrossRef]

19. Zhao, Y.; Duran, R.; Chapiro, J.; Sohn, J.H.; Sahu, S.; Fleckenstein, F.; Smolka, S.; Pawlik, T.M.; Schernthaner, R.; Zhao, L.; et al. Transarterial Chemoembolization for the Treatment of Advanced-Stage Hepatocellular Carcinoma. J. Gastrointest. Surg. 2016, 20, 2002-2009. Available online: https:/ / pubmed.ncbi.nlm.nih.gov/27714643/ (accessed on 28 December 2020). [CrossRef]

20. Lv, W.-F.; Liu, K.C.; Lu, D.; Zhou, C.Z.; Cheng, D.L.; Xiao, J.K.; Zhang, X.M.; Zhang, Z.F. Transarterial chemoembolization for hepatocellular carcinoma combined with portal vein tumor thrombosis. Cancer Manag. Res. 2018, 10, 4719-4726. Available online: http:/ / www.ncbi.nlm.nih.gov/pubmed/30410405 (accessed on 20 November 2020). [CrossRef]

21. Schütte, K.; Schinner, R.; Fabritius, M.P.; Möller, M.; Kuhl, C.; Iezzi, R.; Öcal, O.; Pech, M.; Peynircioglu, B.; Seidensticker, M.; et al. Impact of Extrahepatic Metastases on Overall Survival in Patients with Advanced Liver Dominant Hepatocellular Carcinoma: A Subanalysis of the SORAMIC Trial. Liver Cancer 2020, 9, 771-786. Available online: https:// pubmed.ncbi.nlm.nih.gov/33442545/ (accessed on 17 April 2021). [CrossRef]

22. Lencioni, R.; Llovet, J.M.; Han, G.; Tak, W.Y.; Yang, J.; Guglielmi, A.; Paik, S.W.; Reig, M.; Chau, G.Y.; Luca, A.; et al. Sorafenib or placebo plus TACE with doxorubicin-eluting beads for intermediate stage HCC: The SPACE trial. J. Hepatol. 2016, 64, 1090-1098. Available online: https:/ / pubmed.ncbi.nlm.nih.gov/26809111/ (accessed on 21 December 2020). [CrossRef] 
23. Liu, K.C.; Hao, Y.H.; Lv, W.F.; Jia, W.D.; Ji, C.S.; Zhou, C.Z.; Cheng, D.L.; Xu, S.B.; Gao, Z.G.; Su, M.X.; et al. Transarterial chemoembolization combined with sorafenib in patients with BCLC stage C hepatocellular carcinoma. Drug Des. Dev. Ther. 2020, 14, 3461-3468. Available online: https:/ / pubmed.ncbi.nlm.nih.gov/32904650/ (accessed on 22 December 2020). [CrossRef] [PubMed]

24. Lee, S.W.; Lee, T.Y.; Peng, Y.C.; Yang, S.S.; Yeh, H.Z.; Chang, C.S. The therapeutic benefits of combined sorafenib and transarterial chemoembolization for advanced hepatocellular carcinoma. J. Dig. Dis. 2020, 21, 287-292. [CrossRef] [PubMed]

25. Varghese, J.; Kedarisetty, C.K.; Venkataraman, J.; Srinivasan, V.; Deepashree, T.; Uthappa, M.C.; Ilankumaran, K.; Govil, S.; Reddy, M.S.; Rela, M. Combination of TACE and sorafenib improves outcomes in BCLC stages B/C of hepatocellular carcinoma: A single centre experience. Ann. Hepatol. 2017, 16, 247-254. Available online: https://pubmed.ncbi.nlm.nih.gov/28233748/ (accessed on 17 April 2021). [CrossRef] [PubMed]

26. Kudo, M.; Ueshima, K.; Ikeda, M.; Torimura, T.; Tanabe, N.; Aikata, H.; Izumi, N.; Yamasaki, T.; Nojiri, S.; Hino, K.; et al. Randomised, multicentre prospective trial of transarterial chemoembolisation (TACE) plus sorafenib as compared with TACE alone in patients with hepatocellular carcinoma: TACTICS trial. Gut 2020, 69, 1492-1501. Available online: https://pubmed.ncbi. nlm.nih.gov/31801872/ (accessed on 29 December 2020). [CrossRef]

27. Kudo, M.; Finn, R.S.; Qin, S.; Han, K.H.; Ikeda, K.; Piscaglia, F.; Baron, A.; Park, J.W.; Han, G.; Jassem, J.; et al. Lenvatinib versus sorafenib in first-line treatment of patients with unresectable hepatocellular carcinoma: A randomised phase 3 non-inferiority trial. Lancet 2018, 391, 1163-1173. [CrossRef]

28. Shimose, S.; Iwamoto, H.; Tanaka, M.; Niizeki, T.; Shirono, T.; Noda, Y.; Kamachi, N.; Okamura, S.; Nakano, M.; Suga, H.; et al. Alternating lenvatinib and trans-arterial therapy prolongs overall survival in patients with inter-mediate stage hepatocellular carcinoma: A propensity score matching study. Cancers 2021, 13, 160. Available online: https:// pubmed.ncbi.nlm.nih.gov/3346 6496/ (accessed on 15 February 2021). [CrossRef]

29. Finn, R.S.; Qin, S.; Ikeda, M.; Galle, P.R.; Ducreux, M.; Kim, T.Y.; Kudo, M.; Breder, V.; Merle, P.; Kaseb, A.O.; et al. Atezolizumab plus Bevacizumab in Unresectable Hepatocellular Carcinoma. N. Engl. J. Med. 2020, 382, 1894-1905. [CrossRef]

30. Cheng, A.L.; Hsu, C.; Chan, S.L.; Choo, S.P.; Kudo, M. Challenges of combination therapy with immune checkpoint inhibitors for hepatocellular carcinoma. J. Hepatol. 2020, 72, 307-319. Available online: https:/ / pubmed.ncbi.nlm.nih.gov/31954494/ (accessed on 15 February 2021). [CrossRef] 